\title{
Relationship between Plasma Folate and Homocysteine Concentrations in Alcoholics According to Liver Enzyme Activity
}

\author{
Bogdan CYLWIK $^{1}$, Lech ChrosteK ${ }^{1}$, Marta DANILUK ${ }^{2}$, Zbigniew SuPronowicZ ${ }^{2}$ \\ and Maciej SZMITKOWSKI ${ }^{1}$ \\ ${ }^{1}$ Department of Biochemical Diagnostics, Medical University, Bialystok, Waszyngtona 15A, \\ 15-274 Bialystok, Poland \\ ${ }^{2}$ Department of Detoxification, Psychiatric Hospital, Choroszcz, Poland
}

(Received May 12, 2009)

\begin{abstract}
Summary The aim of this study was to evaluate the relationship between folate and homocysteine levels in alcoholics taking into consideration the liver enzyme activity as sensitive markers of hepatocellular injury. Folate and homocysteine concentrations did not differ between alcoholics classified according to the liver enzyme activity. The association between folate and homocysteine levels exists in the alcoholics with normal liver enzyme activity and in the controls. Therefore, we concluded that before the liver hepatocellular injury due to alcohol abuse, the correlation between folate and homocysteine concentrations in alcoholics exists as in the healthy controls. In the presence of hepatocellular injury, the association disappears.
\end{abstract}

Key Words folate, homocysteine, alcoholics

The liver plays a crucial role in the metabolism of homocysteine; therefore the metabolism of homocysteine in the presence of liver disease may be altered ( 1 , 2). However, there is no information about plasma homocysteine and folate levels in alcoholic patients in relation to hepatocellular injury. The aim of the present study was to investigate the relationship between levels of serum folate and homocysteine in chronic alcoholics, taking into consideration the liver cell injury evaluated by the cytoplasmic and membrane-bound enzyme activity.

The experimental group comprised 80 consecutive chronic alcoholic men aged 23-77 y (mean: 43 y), who were diagnosed with alcohol dependence according to the International Classification of Diseases (ICD-10), category F-10. All patients were interviewed regarding their history of alcohol abuse and classified according to clinical and biochemical data. The control group of 40 healthy men (range: 24-65; mean: 40 y) was also studied. All subjects gave their consent to participate in the studies. The study was approved by the local bioethics committee.

The blood samples were drawn within $12 \mathrm{~h}$ after admission. Tubes were immediately centrifuged at $1,500 \times g$ for $10 \mathrm{~min}$ at $4^{\circ} \mathrm{C}$ in order to eliminate the homocysteine efflux from red blood cells to serum and then sera were stored at $-87^{\circ} \mathrm{C}$ until they were analyzed. The samples for folate evaluation were stored in a refrigerator for no longer than 1 mo. Total homocysteine and folate concentrations were measured using the chemiluminescent microparticle immunoassay

E-mail: cylwikb@umwb.edu.pl technology (CMIA) (Homocysteine, Abbott, Wiesbaden, Germany; Folate, Abbott Ireland, Longford, Ireland) adapted to the Architect i2000 analyzer (Abbott, USA). Alanine aminotransferase (ALT), aspartate aminotransferase (AST) and $\gamma$-glutamyltransferase (GGT) were determined following standard procedures at the Department of Laboratory Diagnostics of University Hospital in Bialystok. The distribution of all variables was tested using the Shapiro-Wilk test. Because all variables were not normally distributed $(p<0.001$ for all tests), the results are presented as median and ranges, and nonparametric statistics were also performed.

The occurrence of hyperhomocysteinemia in alcoholics oscillates in the range between 17 and $30 \%(3,4)$ but the occurrence of folate deficiency fluctuates between 11 and $87 \%$ (5-7). The comparison of these values may suggest that other factors, besides folate status, might also play a role in hyperhomocysteinemia in chronic alcohol abuse. One of them is the presence of liver disease $(1,2,6)$. The prevalence of low serum folate levels in our study was $42.5 \%$, and high homocysteine concentrations, $60 \%$. Our results showed that folate and homocysteine concentrations in alcoholics did not differ between subjects with normal and high enzyme activity, although the mean folate levels were significantly decreased while homocysteine concentrations were significantly increased in alcoholics (Table 1). On the other hand, the levels of homocysteine in alcoholics with low folate levels were higher than in the subjects with normal folate concentrations.

Many studies showed an inverse correlation between serum concentration of homocysteine and folate (8). In our study there was no correlation between these 
3) Selhub J, Jacques PF, Boston AG, Wilson PW, Rosenberg JH. 2000. Relationship between plasma homocysteine and vitamin status in the Framingham study population. Impact of folic acid fortification. Pub Health Rev $\mathbf{2 8}$ : 117-145.

4) Blasco C, Caballeria J, Deulofeu R, Ligona A, Pares A, Luis JM, Gual A, Rodes J. 2005. Prevalence and mechanisms of hyperhomocysteinemia in chronic alcoholics. Alcohol Clin Exp Res 29: 1044-1048.

5) Halsted CH. 1980. Folate deficiency in alcoholism. Am J Clin Nutr 33: 2736-2740.
6) Fernando OV, Grimsley EW. 1998. Prevalence of folate deficiency and macrocytosis in patients with and without alcohol-related illness. South Med J 91: 721-725.

7) Halsted CH, Villanueva JA, Devlin AM, Chandler CJ. 2002. Metabolic interactions of alcohol and folate. I Nutr 132: 2367S-2372S.

8) Jacques PF, Boston AG, Wilson PW, Rich S, Rosenberg IH, Selhub J. 2001. Determinants of plasma total homocysteine concentration in the Framingham Offspring cohort. Am J Clin Nutr 73: 613-621. 